Universidade Tecnológica Federal do Paraná - UTFPR

Campus Ponta Grossa - Paraná - Brasil

ISSN: 1981-3686/ v. 04, n. 02: p. 122-131, 2008

DOI: $10.3895 / \mathrm{S} 1981-36862010000200001$
Revista Brasileira deTecnologia

Agroindustrial

\title{
BOAS PRÁTICAS DE FABRICAÇÃO EM SERVIÇOS DE ALIMENTAÇÃO SITUADOS NO ESTADO DO PARANÁ
}

\section{GOOD MANUFACTURING PROCEDURES IN FOOD SERVICE ESTABLISHMENTS SITUATED IN THE PARANA STATE}

\footnotetext{
Krischina Singer Aplevicz ${ }^{1}$; Liz Elaine Sowek Santos ${ }^{2}$; Eliana Aparecida Fagundes Queiroz Bortolozo ${ }^{3}$ ${ }^{1}$ Instituto Federal de Educação, Ciência e Tecnologia -IFSC -Florianópolis - Brasil -krischina@ifsc.edu.br ${ }^{2}$ Louis Dreyfus Commodities Brasil S.A - Ponta Grossa - Brasil - lizesantos@ig.com.br

${ }^{3}$ Universidade Tecnológica do Paraná - UTFPR - Ponta Grossa - Brasil - bortolozo@ utfpr.edu.br
}

\section{Resumo}

O presente estudo tomou por objetivo avaliar as condições de higiene no preparo e distribuição de alimentos, em trinta e quatro estabelecimentos processadores de alimentos (Serviços de Alimentação) localizados no estado do Paraná, no que tange às boas práticas de fabricação. $O$ quesito qualidade foi avaliado com base em um guia de verificação, ou check-list, elaborado segundo o Programa de Alimento Seguro (PAS) e em conformidade com a legislação vigente. As condições observadas na grande maioria dos estabelecimentos avaliados podem ser consideradas precárias. A pesquisa revelou que as empresas de serviço de alimentação estudadas não seguem as normas vigentes de boas práticas de fabricação. Nos itens - recursos humanos; ambiente; instalação; saneamento; equipamentos; utensílios; produção - foram constatadas diversas não conformidades. Foram encontradas várias deficiências críticas, como, por exemplo, a higienização inadequada das mãos. A falta de informação por parte dos comerciantes, além da ausência de um responsável técnico, demonstra riscos potenciais de prejuízo à saúde do consumidor.

Palavras chaves: serviços de alimentação; boas práticas de alimentação; higiene dos alimentos.

\section{Introdução}

A manutenção da integridade e saúde de todo ser vivo depende da ingestão diária de alimentos que sejam quantitativa e qualitativamente adequados, saudáveis, e que não coloquem em risco a saúde do consumidor. Isto requer que se estabeleçam normas, limites e padrões, exercendo tarefas de inspeção, controle, fiscalização e vigilância, a fim de assegurar a qualidade dos alimentos (VALEJO et al., 2003).

A qualidade sanitária do alimento depende do controle exercido sobre os perigos químicos, físicos e biológicos, que permeiam todas as etapas da cadeia alimentar, iniciada na produção e finalizada no consumo (GÓES et al., 2001; SILVA, 2001; VEIGA et al., 2006; WURLITZE, 2006).

No âmbito internacional, a segurança alimentar é preconizada por organismos e entidades como a Organização para Agricultura e Alimentos (FAO) e a Organização Mundial da Saúde 
(OMS). No âmbito nacional, fica a cargo do Ministério da Saúde (MS), o Ministério da Agricultura, Pecuária e Abastecimento (MAPA) e o Instituto Brasileiro de Defesa do Consumidor (IDEC) (CAVALLI, 2006).

O Comitê da Organização das Nações Unidas para Agricultura e Alimentação (WHO/FAO) admite que doenças oriundas de alimentos contaminados representam, provavelmente, a maior questão de saúde no mundo contemporâneo (AKUTSU et al., 2006). Nos centros urbanos, o hábito alimentar vem sofrendo alterações, em virtude da diminuição do tempo disponível para a preparação e ingestão dos alimentos. A emancipação da mulher na sociedade e sua crescente inserção no mercado de trabalho, o desenvolvimento das cidades e a falta de tempo disponível para preparar sua própria refeição tornam cada vez maior o número de pessoas que se alimentam fora de casa (SOUZA et al., 2003; QUEIROZ et al., 2001).

No Brasil, estima-se que, de cada cinco refeições, uma é feita fora de casa; na Europa, duas em cada seis; e nos EUA, uma em cada duas. Esses números indicam que ainda pode ocorrer um grande aumento e desenvolvimento dos estabelecimentos que produzem alimentos para consumo imediato no país (ARAÚJO e CARDOSO, 2002). Tais estabelecimentos incluem unidades de produção de porte e tipos de organização diferentes entre si, como restaurantes comerciais, restaurantes de hotéis, serviços de motéis, coffee shops, lanchonetes, cozinhas industriais, fast food, catering e cozinhas hospitalares (PAYNE, 1994).

Para controlar os surtos e as Doenças Veiculadas por Alimentos (DVAs) em estabelecimentos que processam alimentos, faz-se necessário adotar práticas de higiene que reduzam o risco que os produtos prontos representam para os consumidores.

São as Boas Práticas de Fabricação ou Manipulação (BPF/M) de Alimentos que, uma vez implantadas e registradas em manual, asseguram os parâmetros básicos de qualidade, assim como os procedimentos de elaboração dos alimentos e de higiene que, quando necessários, devem ser descritos (SENAC, 2001). A elaboração do Manual das BPF deve seguir roteiro atendendo a requisitos estabelecidos pela Portaria 1428/MS (BRASIL, 1993). Em setembro de 2004, entrou em vigência no Brasil a Resolução RDC 216, do Ministério da Saúde, que dispõe sobre Regulamento Técnico de Boas Práticas para Serviços de Alimentação. Este dispositivo aplica-se aos serviços de alimentação que realizam algumas das seguintes atividades: manipulação, preparação, fracionamento, armazenamento, distribuição, transporte, exposição à venda e entrega de alimentos preparados para consumo, tais como cantinas, bufês, comissárias, confeitarias, cozinhas industriais, cozinhas institucionais, delicatessens, lanchonetes, padarias, pastelarias, restaurantes, rotisserias e congêneres (BRASIL, 2004).

Apesar da evolução científica e mesmo da legislação sobre alimentos, é ainda elevada a taxa de doenças transmitidas por alimentos, decorrentes da falta de higiene em sua produção ou 
manipulação (EDUARDO e MIRANDA, 2006). A contaminação alimentar pode manifestar-se de diversas maneiras. Os sintomas variam de acordo com o microrganismo ou organismo, com o veneno que estes produzem, com a parte do corpo que foi afetada, com o estado de saúde do indivíduo (RICHARDS, 2002).

Dentre as doenças transmitidas pelos alimentos, estão as de origem física, química e microbiológica. As toxinfecções alimentares de origem microbiana têm sido reconhecidas como o problema de saúde pública mais abrangente no mundo atual, sendo causa importante na diminuição da produtividade, das perdas econômicas que afetam os países, empresas e simples consumidores (FAÇANHA et al., 2003; MESQUITA et al., 2006).

Este estudo teve como objetivo avaliar as condições de higiene no preparo e distribuição de alimentos, em 34 estabelecimentos processadores de alimentos (Serviços de Alimentação), instalados na região dos Campos Gerais, estado do Paraná, no que tange às boas práticas de fabricação.

\section{Material e Métodos}

Foram escolhidos, aleatoriamente, 34 estabelecimentos situados na região dos Campos Gerais, estado do Paraná. A avaliação foi feita no ano de 2006, incluindo a classificação como restaurantes/ hotéis (14), restaurantes comerciais (13), padarias/ docerias (7).

Para avaliar as Boas Práticas (BP) dos estabelecimentos foi utilizado na pesquisa um instrumento de medição de qualidade, ou seja, um guia de verificação ou check-list, elaborado com base no Programa Alimento Seguro (PAS) para implantação das BP em estabelecimentos produtores de alimentos do segmento mesa (SENAC, 2001), na RDC 216, de 2004 (BRASIL, 2004) e na RDC 275 de 2002 (BRASIL, 2002). Os aplicadores do check-list eram treinados pelo programa PAS. Durante as visitas, o check-list foi preenchido pelo aplicador, em face das suas observações no próprio local, complementadas por informações fornecidas pelo proprietário ou administrador do estabelecimento.

Dos 112 itens abordados no check-list, 64 são considerados imprescindíveis ou críticos para a produção segura de alimentos, ou seja: aqueles considerados críticos para a proteção contra surtos de doenças alimentares e que necessitam de correção imediata quando não atendidos (TOMICH et al., 2005). As opções de respostas para o preenchimento do check-list foram: "Conforme" (C) quando não houve atendimento ao item observado; "Não Conforme" (NC) - quando o estabelecimento apresentou Não-conformidade quanto ao item observado; "Não Aplicável” (NA) - 
quando o item foi considerado não pertinente ao local pesquisado. As questões tendo como resposta a opção NA não foram estatisticamente avaliadas.

\section{Resultados e discussão}

A análise do check-list aplicado nas empresas pesquisadas revelou inadequação das mesmas à norma RDC 216/MS (BRASIL, 2004). Foi constatado que das 34 empresas apenas 3 contam com um responsável técnico, ou seja, uma pessoa da área de alimentos ou nutrição, capacitada para coordenar os aspectos higiênico-sanitários. Nas demais, esta função é exercida pelos proprietários, gerentes ou chefs, que nem sempre possuem capacitação técnica. A ausência deste responsável técnico pode resultar no atraso do aperfeiçoamento dos sistemas de qualidade.

$\mathrm{Na}$ área dos recursos humanos foram avaliados 7 itens, a saber: treinamentos, higiene corporal, higienização das mãos e uso de uniformes pelos funcionários e visitantes. Os índices de Não-conformidades variaram entre $33,3 \%$ e $100 \%$ (Tabela 1 ).

Tabela 1 - Resultado das Não-conformidades (NC) de recursos humanos, reveladas em check-list aplicado em 34 estabelecimentos da região dos Campos Gerais

\begin{tabular}{lccc}
\hline Item avaliado & Restaurante hotel & $\begin{array}{c}\text { Restaurante comercial/ } \\
\text { churrascaria/ } \\
\text { pizzaria/lanchonete }\end{array}$ & Padaria/ doceria \\
\hline treinamento e reciclagem & 50,0 & 82,4 & 100,0 \\
higiene corporal & 42,9 & 70,6 & - \\
procedimento higienização mãos & 100,0 & 94,1 & 100,0 \\
higienização correta das mãos & 85,7 & 82,4 & 100,0 \\
exames médicos & 35,7 & 70,6 & 66,7 \\
uniformes & 42,9 & 58,8 & 33,3 \\
visitantes sem uniforme & 100,0 & 100,0 & 100,0 \\
\hline
\end{tabular}

Nenhum estabelecimento faz uso de uniforme para visitantes, na área de produção. O setor hoteleiro destacou-se no item treinamento, apresentando $50 \%$ de não-conformidades, quando comparado a $82,4 \%$ para restaurantes comercias e $100 \%$ para panificadoras. A busca pela melhoria constante na qualidade dos serviços, em razão da exigência do mercado, propicia o alto índice de treinamentos no setor hoteleiro. Já nos restaurantes e padarias, em virtude da maioria ser gerenciada pelos proprietários, há desconhecimento ou mesmo falta de interesse pela normatização vigente.

Dentre as deficiências críticas, a higienização das mãos de forma inadequada representou os maiores índices de não-conformidades, com $85,7 \%$ nos restaurantes de hotéis, $82,4 \%$ em restaurantes comerciais e $100 \%$ nas padarias. Snyder Junior (1993) afirmou que, para o alimento 
estar seguro para o consumo, as mãos do manipulador devem estar limpas e o manuseio deve ser mínimo.

Há, ainda, certa resistência dos manipuladores de alimentos no item da higiene corporal, com irregularidades detectadas em $70,6 \%$ dos restaurantes comerciais. As principais deficiências encontradas foram: cabelos desprotegidos, uso de brincos e anéis, esmalte nas unhas. Este quadro observado demonstra a necessidade de treinamentos permanentes dirigidos a manipuladores de alimentos, alertando-os para os riscos decorrentes dessas falhas.

No item ambiente, instalações e saneamento (Tabela 2) foram observados aspectos relacionados à área externa: controle de pragas, paredes, pisos, ralos, portas e janelas, lixeira, luminária, pias para higienização de mãos, sanitários e vestiários, abastecimento de água e escala de limpeza. Os estabelecimentos comerciais mostraram condições desfavoráveis quanto ao uso de lixeira com tampa e com pedal, a saber:78,6\% no grupo de hotéis; 82,4\% nos restaurantes comerciais e $100 \%$ nas padarias. Na área de produção, o uso de ralos com fechamento é efetivo apenas em cerca de $34,8 \%$ dos estabelecimentos pesquisados.

Tabela 2 - Resultado das Não-conformidades (NC) de ambiente, instalações e saneamento, conforme check-list aplicado em 34 estabelecimentos da região dos Campos Gerais

\begin{tabular}{|c|c|c|c|}
\hline \multirow{2}{*}{$\begin{array}{l}\text { Item avaliado } \\
\text { Ambiente, instalações e saneamento }\end{array}$} & \multirow{2}{*}{$\begin{array}{c}\text { Restaurante } \\
\text { hotel }\end{array}$} & \multirow{2}{*}{$\begin{array}{c}\text { Restaurante } \\
\text { comercial/ } \\
\text { churrascaria/ } \\
\text { pizzaria/ } \\
\text { anchonete } \\
\end{array}$} & \multirow{2}{*}{$\begin{array}{r}\text { Padaria/ } \\
\text { doceria }\end{array}$} \\
\hline & & & \\
\hline área externa: sucata e lixo animais & 57,1 & 29,4 & 66,7 \\
\hline controle de pragas & 7,1 & 29,4 & 66,7 \\
\hline contato superfície limpa x suja & 21,4 & 52,9 & - \\
\hline parede cor clara, limpa e impermeável & - & 5,9 & 66,7 \\
\hline piso limpo, claro, antiderrapante e conservado & 14,3 & 47,1 & 33,3 \\
\hline ralo com proteção & 64,3 & 64,7 & 66,7 \\
\hline forro ou teto em bom estado & 7,1 & 11,8 & 66,7 \\
\hline porta ajustada aos batentes e fechamento automático & 21,4 & 35,3 & 100,0 \\
\hline janelas com telas em perfeitas condições e ajustadas aos batentes & 42,9 & 58,8 & 66,7 \\
\hline lixeiras sem contato manual e com tampa & 78,6 & 82,4 & 100,0 \\
\hline luminárias protegidas & 85,7 & 94,1 & 100,0 \\
\hline pia para higienização das mãos & 85,7 & 94,1 & 100,0 \\
\hline sanitários perfeitas condições & 64,3 & 76,5 & 66,7 \\
\hline sanitários não se comunicam produção e separados por sexo & 7,1 & 17,7 & - \\
\hline limpeza e procedimento da caixa de gordura (fora da produção) & 42,9 & 29,4 & - \\
\hline limpeza e procedimento da caixa d'água & 21,4 & 58,8 & 33,3 \\
\hline vassouras em contato direto com o chão sem local apropriado & 64,3 & 47,1 & 33,3 \\
\hline vestiário em perfeitas condições e organizado & 35,7 & 41,2 & 33,3 \\
\hline possuem escala de limpeza & 78,6 & 94,1 & 100,0 \\
\hline
\end{tabular}

A limpeza semestral das caixas foi registrada apenas em 58,8\% dos restaurantes comerciais. Destes, 29,4\% apresentaram irregularidades na limpeza, na frequência e no procedimento de limpeza das caixas de gorduras, com a higienização sendo feita pelos funcionários do próprio 
restaurante. A avaliação destes critérios é relevante, em virtude de representarem itens críticos para a produção de alimentos.

A Tabela 3 refere-se à avaliação dos equipamentos, utensílios, bancadas e manutenção preventiva. Dentre as empresas analisadas, nenhuma possui um programa de manutenção preventiva implantado. As manutenções preventivas evitam problemas nos equipamentos, reduzindo, assim, as possíveis perdas na produção. Foi detectada apenas a existência da manutenção corretiva nas empresas, não havendo registros da prática efetuada.

Tabela 3 - Resultado das Não-conformidades (NC) de equipamento e utensílios, conforme check-list aplicado em 34 estabelecimentos da região dos Campos Gerais

\begin{tabular}{lccc}
\hline Item avaliado & $\begin{array}{c}\text { Restaurante } \\
\text { hotel }\end{array}$ & $\begin{array}{c}\text { Restaurante } \\
\text { comercial/ } \\
\text { churrascaria/ } \\
\text { pizzaria/ } \\
\text { lanchonete }\end{array}$ & $\begin{array}{c}\text { Padaria/ } \\
\text { doceria }\end{array}$ \\
\hline equipamentos limpos e conservados & & 47,1 & 100,0 \\
utensílios lisos, resistentes & 35,7 & 38,8 & 3,3 \\
bancadas limpas, lisas, resistentes & 35,7 & 14,3 & 66,7 \\
programa manutenção preventiva e registro & 100,0 & 100,0 & 100,0 \\
procedimentos higienização utensílios e equipamentos disponíveis & 78,6 & 76,5 & 100,0 \\
utensílios de mesa são protegidos até a produção & 14,3 & 41,2 & - \\
\hline
\end{tabular}

Do total dos restaurantes comerciais, $58,8 \%$ estão em desacordo quanto ao item utensílios. Muitas empresas utilizam utensílios de madeira (colheres, tábuas, rolos ou socadores), mesmo conhecendo a proibição do uso. Em várias empresas se verificam utensílios apresentando ranhuras e bolores.

Na Tabela 4 podem ser visualizados os 23 aspectos relacionados à produção, tais como embalagens externas; avaliação das matérias-primas; estoque; produtos de limpeza; contaminação cruzada; descongelamento; dessalgue; sobras, entre outros. Nas não-conformidades listadas, observa-se que a maioria das empresas não identifica corretamente os alimentos, correspondendo a um índice de $85,7 \%$ nos hotéis, 94,1\% nos restaurantes comerciais e $100 \%$ nas padarias. A legislação exige dos estabelecimentos a colocação de etiquetas com todas as identificações completas dos produtos, para que, em caso de um provável surto alimentar, a empresa possa rastrear o produto e identificar o alimento contaminado.

$\mathrm{O}$ descongelamento de alimentos também apresenta deficiências. É realizado à temperatura ambiente em 70,6\% dos restaurantes comerciais, assim contrariando a recomendação de que seja feito sob refrigeração ou no forno microondas. O recongelamento de alimentos foi detectado em 33,3\% das padarias; nos hotéis e restaurantes comerciais esses índices são menores, revelando maior responsabilidade quanto à observância das normas específicas. 
Dos restaurantes comerciais, 58,8\% elaboram produtos utilizando ovos crus e palmito in natura sem um tratamento térmico adequado. A utilização do ovo cru pode causar contaminação dos alimentos com Salmonella Enteritidis. Simões et al. (2001) estudaram 115 surtos alimentares causados por esta bactéria e concluíram que ovos, seus derivados e pratos contendo ovos mal cozidos foram os principais responsáveis pelos surtos. O palmito contaminado com a bactéria Clostridium botulinum provocou 65 casos de botulismo no Brasil, segundo pesquisa com base nos dados de mortalidade ocorrida entre 1979 e 1998 (CVE/SES-SP, 2007).

Tabela 4 - Resultado das Não-conformidades (NC) de aspectos de produção, conforme check-list aplicado em 34 estabelecimentos da região dos Campos Gerais

\begin{tabular}{|c|c|c|c|}
\hline Item avaliado & \multirow{2}{*}{$\begin{array}{l}\text { Restaurante } \\
\text { hotel }\end{array}$} & \multirow{2}{*}{$\begin{array}{l}\text { Restaurante } \\
\text { comercial/ } \\
\text { churrascaria/ } \\
\text { pizzaria/lanchonete }\end{array}$} & \multirow{2}{*}{$\begin{array}{l}\text { Padaria/ } \\
\text { doceria }\end{array}$} \\
\hline Aspectos de produção & & & \\
\hline substituição das embalagens externas dos produtos & 71,4 & 47,1 & 100,0 \\
\hline na entrega MP são avaliadas (temperatura, rotulagem íntegra) & 7,1 & 35,3 & 33,3 \\
\hline produtos não-conformes são devolvidos, identificados e separados & 14,3 & - & 66,7 \\
\hline estoque em prateleira limpa,conservado, protegido com telas & 64,3 & 58,8 & 100,0 \\
\hline controle de estoque (PVPS) & 21,4 & 41,2 & 33,3 \\
\hline produtos de limpeza separados dos alimentícios & 28,6 & 23,5 & 33,3 \\
\hline produtos de limpeza identificados e diluídos & 35,7 & 23,5 & - \\
\hline produtos descartáveis protegidos & 21,4 & 5,9 & - \\
\hline perecíveis com temperatura controlada na distribuição & 85,7 & 64,7 & - \\
\hline risco de contaminação cruzada & 78,6 & 88,2 & 66,7 \\
\hline produtos abertos identificados e armazenados corretamente & 85,7 & 94,1 & 100,0 \\
\hline descongelamento forma segura & 35,7 & 70,6 & 33,3 \\
\hline recongelamento de alimentos & 7,1 & 5,9 & 33,3 \\
\hline dessalgue em condições seguras & 28,6 & 47,1 & - \\
\hline pré-preparo de alimentos no máximo $30 \mathrm{~min}$. em temperatura ambiente & 64,3 & 41,2 & 33,3 \\
\hline produtos pré-preparados mantidos refrigerados até o consumo & 14,3 & 58,8 & 33,3 \\
\hline existem procedimentos de lavagem hortifrutigranjeiros & 71,4 & 82,4 & 33,3 \\
\hline produtos de limpeza com registro no MS & - & 11,8 & - \\
\hline equipamento manutenção quente/frio temp controlada & 35,7 & 47,1 & 100,0 \\
\hline óleos e gorduras utilizar única vez com temp. máxima de $180^{\circ} \mathrm{C}$ ou análises & 42,9 & 35,3 & 33,3 \\
\hline utilizam ovo cru ou palmito in natura & 35,7 & 58,8 & 33,3 \\
\hline utilizam recurso correto para o resfriamento de alimentos & 28,6 & 76,5 & - \\
\hline sobras são reaproveitadas x controle de temperatura & 57,1 & 76,5 & 66,7 \\
\hline
\end{tabular}

Quanto ao item Manual de Boas Práticas (Tabela 5), observa-se que hotéis, restaurantes e padarias, geralmente não possuem este documento, constatando-se deficiência de $85,7 \%, 82,4 \%$ e $100 \%$, respectivamente.

Tabela 5 - Resultado das Não-conformidades (NC) de aspectos de controle de qualidade, cpnforme check-list aplicado em 34 estabelecimentos da região dos Campos Gerais

\begin{tabular}{lccc}
\hline Item avaliado & Restaurante hotel & $\begin{array}{l}\text { Restaurante } \\
\text { comercial/ } \\
\text { churrascaria/ } \\
\text { pizzaria/lanchonete }\end{array}$ & Padaria/ doceria \\
\hline possui manual de boas práticas e POPS & 85,7 & 100,0 \\
coletam amostras & 100,0 & 100,0 & 100,0 \\
controle microbiológico ou físico-químico (água) & 78,6 & 88,2 & 100,0 \\
\hline
\end{tabular}


Todas as empresas devem obrigatoriamente possuir esse documento, para conhecimento e efetivação das normas pertinentes, a fim de garantir condições higiênico-sanitárias satisfatórias. Nenhuma das empresas estudadas adota a prática da coleta de amostras, alegando falta de mão-deobra suficiente, de espaço físico e alto custo das análises.

\title{
4. Conclusão
}

Este estudo demonstrou que as empresas de serviço de alimentação estudadas não seguem as normas vigentes de boas práticas de fabricação. Nos itens como recursos humanos, ambiente, instalação, saneamento, equipamentos, utensílios e produção, foram identificadas várias nãoconformidades.

Dentre as deficiências críticas, a higienização das mãos de forma inadequada apresentou os maiores índices de não-conformidades, com $85,7 \%$ nos restaurantes de hotéis, $82,4 \%$ em restaurantes comerciais e $100 \%$ nas padarias.

Levando-se em conta ser considerada área turística a região estudada, torna-se mais relevante a precariedade da situação encontrada. A falta de informação dos comerciantes, além da ausência de um responsável técnico, demonstra riscos potenciais de prejuízo à saúde do consumidor.

\begin{abstract}
The objective of this study was to evaluate the hygiene conditions in food preparation and distribution in relation to good manufacturing procedures in thirty four food processing establishments (FoodService), located in the state of Paraná. The quality requisite was evaluated under a verification guide or check-list, constructed according to PAS, (Safe Food Program), and in conformity with current legislation. The conditions observed in the majority of the evaluated establishments can be considered precarious. The research revealed that the manufacturing procedures establishments do not follow the good manufacturing procedures. Items like human resources, environment, installation, sanitation, equipments, utensils and production have presented some non conformity. Several critical deficiencies have been found, as for example, inadequate hand sanitization. The establishment owners lack of information in addition to the absence of a technician responsible for the company demonstrate potential damage risks to the consumer health.
\end{abstract}

Key-words: foodservice establishments; good manufacturing procedures; foods hygiene. 


\section{Referências}

AKUTSU, R.; BOTELHO, R.; CAMARGO, E.; SÁVIO, K.; ARAÚJO, W. Adequação das boas práticas de fabricação em serviços de alimentação. Revista de Nutrição, v. 18, n. 3, 2005. DOI: 10.1590/S1415-52732005000300013.

ARAÚJO, W. M. C.; CARDOSO, L. Qualidade dos alimentos comercializados no Distrito Federal, no período de 1997-2001. Dissertação (Mestrado) UNB, Brasília; 2002.

BRASIL. Ministério da Saúde. Agência de Vigilância Sanitária. Resolução n ${ }^{\circ}$ 275, de 21 de outubro de 2002 . In. DIÁRIO OFICIAL DA UNIÃO. Brasília, 06 de novembro de 2002.

BRASIL. Ministério da Saúde, Resolução Agência de Vigilância Sanitária. Resolução no 216, de 15 de setembro de 2004. In. DIÁRIO OFICIAL DA UNIÃOO. Brasília, 16 de setembro de 2004.

BRASIL. Ministério da Saúde, Resolução Agência de Vigilância Sanitária. Resolução nº 1428/MS, de 26 de novembro de 1993. In. DIÁRIO OFICIAL DA UNIÃOO. Brasília, de 02 de dezembro de 1993.

CAVALLI S. B. Segurança alimentar: a abordagem dos alimentos transgênicos. Revista Nutrição, v.14, supl. 0, p. 4146, 2001. doi: 10.1590/S1415-52732001000400007.

CVE/SES-SP - Centro de Vigilância Epidemiológica/Secretaria de Estado da Saúde de São Paulo. Manual das Doenças Transmitidas por Alimentos, 2003, disponível em <http://www.cve.saude.sp.gov.br/htm/hidrica/revnet/revnet_n502.htm>. Acesso em 19 de novembro de 2007.

EDUARDO, M. P.; MIRANDA, I. C. S. Vigilância Sanitária das Tecnologias de Alimentos, disponível em <http://www.saude.sc.gov.br>. Acesso em 15 de agosto de 2006.

FAÇANHA, S. H. F.; MONTE, A. L. S.; FERREIRA, N. D. L.; ALVEZ, T. M.; DIAS, G. M; RIDRIGUÊS, J. M. P; PAULO, A. P. F. Treinamento para Manipuladores de Alimentos em Escolas da Rede Municipal de Ensino da Sede e Distritos do Município de Meruoca, Ceará: Relato de Experiência. Revista Higiene Alimentar, v. 17, n. 106, p. 30-34, 2003.

GÓES, J. A. W.; FURTUNATO, D. M. N; VElOSO, I. S.; SANTOS, J. M. Capacitação dos Manipuladores de Alimentos e a Qualidade da Alimentação Servida. Revista Higiene Alimentar, v. 15, n. 82, p. 20-23, 2001.

MESQUITA, M. O.; DANIEL, A. P.; SACCOL, A. L. F.; MILANI, L. I. G.; FRIES, L. L. M. Qualidade microbiológica no processamento do frango assado em unidade de alimentação e nutrição. Ciência e Tecnologia de Alimentos, v. 26, n. 1, 2006. DOI: 10.1590/S0101-20612006000100031.

QUEIROZ, A.T.A.; RODRIGUES, C.R.; ALVAREZ, G.G.; TAKISAKA, L.T. Boas práticas de fabricação em restaurantes "Self-service a quilo" - Aspectos Gerais - São Paulo, 1999. Revista NET-DTA, disponível em <http://www.cve.saude.sp.gov.br/htm/hidrica/revnet/revnet_n1.htm\#pg1 >. Acesso em 07 de julho de 2007.

PAYNE-PALACIO, J. West's and wood's introduction to foodservice. New York: MacMillan, 1994.

RICHARDS, N. S. P. S. Segurança Alimentar: Como prevenir contaminações na indústria. Revista Food Ingredients, v. 3, n. 18, p. 16-30, 2002.

SENAC/DN. Guia passo a passo: Implantação de Boas Práticas e Sistema APPCC. Qualidade e Segurança Alimentar. Projeto APPCC Mesa. Convênio CNC/CNI/SEBRAE/ANVISA. Rio de Janeiro, 2001a.

SILVA JR, E. A. HACCP (APPCC). Análise de Perigos e Controle dos Pontos Críticos. In_ Manual de Controle Higiênico-Sanitário em Alimentos. São Paulo, 2001.

SIMÕES, M.; MARQUES, E.G.L.; ROCHA, M.M.M.; PRANDI, M.A.G.; PISANI B. Surtos alimentares por Salmonella enteritidis ocorridos na região de Campinas no período de março de 1995 a março de 2001. In: XXI Congresso Brasileiro de Microbiologia, Foz do Iguaçu, p.413, 2001.

SNYDER JUNIOR, P.O. Developing a total quality management based food safety program for a chilled food system. Cleveland: Cleveland Range and Hospitality Institute of Technology and Management, 1993. 
SOUZA, S. S.; PELIOCINI, M. C. F.; PEREIRA, I.M.T.B. A Vigilância Sanitária de Alimentos como Instrumento de Promoção de Saúde: relato de experiência de educação em saúde para o comércio varejista de alimentos e construção de um projeto de parceria. Revista Higiene Alimentar, n. 113, v. 17, p. 33-37, 2003.

TOMICH, R. G. P.; TOMICH, T. R.; AMARAL, C. A. A.; JUNQUEIRA, R. G.; PEREIRA, A. J. G. Metodologia para Avaliação das Boas Práticas de Fabricação em Indústrias de Pão de Queijo. Ciência e Tecnologia de Alimentos, Campinas, v. 25, n. 1, p. 115- 120, 2005. doi: 10.1590/S0101-20612005000100019.

VAlEJO, F. A. M.; ANDRÉS, C. R.; MANTOVAN, F. B.; RISTER, G. P.; SANTOS, G. D.; ANDRADE, F. F. Vigilância Sanitária: Avaliação e Controle da Qualidade dos Alimentos. Revista Higiene Alimentar, v. 17, n. 106, p. 16-20, 2003.

VEIGA, C. F.; DORO, D. L.; OLIVEIRA, K. M. P. Estudo das condições sanitárias dos Estabelecimentos Comerciais de Manipulação de Alimentos do Município de Maringá, PR. Revista Higiene Alimentar, v. 20, n. 138, p. 28 -36, 2006.

WURLITZER, N.J. Industrialização de Alimentos Visando a Saúde do Consumidor. Disponível em <http://www.firjan.org.br>. Acesso em 17 de outubro de 2006.

\section{Dados dos autores}

Nome completo: Krischina Singer Aplevicz

Filiação institucional: Instituto Federal de Educação, Ciência e Tecnologia de Santa Catarina (IF-

$\mathrm{SC})$

Departamento: Turismo e Hospitalidade

Função ou cargo ocupado: Professor

Titulação: Mestre em Ciência e Tecnologia de Alimentos

Endereço: Rua 14 de julho, 150 Coqueiros - 88075-000 - Florianópolis-SC

Telefones para contato: (48) 3271-1423 e 9915-2242

e-mail:krischina@ifsc.edu.br

Nome completo: Liz Elaine Sowek Santos

Filiação institucional: Louis Dreyfus Commodities Brasil S. A

Função ou cargo ocupado: Nutricionista Divisional

Titulação: Pós graduada em Nutrição Esportiva e Nutrição Funcional

Endereço: Rua Afonso Pena ,331 ap 13 Vila estrela Ponta Grossa Paraná CEP 84040-170

Telefones para contato: 42882809644230271988

e-mail: lizesantos@ig.com.br

Nome completo: Eliana Aparecida Fagundes Queiroz Bortolozo

Filiação institucional: Universidade Tecnológica Federal do Paraná

Departamento: Coordenação de Alimentos

Função ou cargo ocupado: Professor

Titulação: Mestre

Endereço: Rua Euzébio da Mota, 361, Ponta Grossa, Paraná, Cep: 84051530

Telefones para contato: 423224512491222630

e-mail:bortolozo@utfpr.edu.br 